\title{
Problems of the Language in Religion
}

\author{
Yuliani \\ UIN Sunan Gunung Djati Bandung, Indonesia \\ Email: yuliani@uinsgd.ac.id
}

\begin{abstract}
The purpose of this paper is to describe the problems related to language that arise in religion. Religion in its teachings and dissemination cannot escape from the use of language, especially in every religious scripture that exists. The use and choice of language in religion is also often the cause of the complexity of realizing tolerance in religion. This research uses available literature studies related to language and religion. The author concludes that Language is a key player in a religion in terms of both teaching and teaching.
\end{abstract}

Keywords: language, religion, conflict.

\section{A. INTRODUCTION}

Language is "a system of signs that express ideas. Thus language can be compared with writing, mute alphabet, symbolic rites, manners, signs of tolerance and so on. But language is the most important system compared to others. "From this formulation, de Saussure's linguistic theory then developed in the direction of two regions, structuralism on the one hand and semiotics on the other (de Saussure, 2011).

In this framework, religion might be seen as a sign system that expresses meaning, which is related to the belief in transcendent matters. De Saussure distinguishes language patterns (language) that apply to various sign systems, and language in a special sense (langue) as we know it in English, French, Indonesian and so on. So religion can also be considered as a pattern of language, which uses distinctive signs that follow specific rules of the game. In this case, the language of religion becomes exclusive, like any other language, and can only be a means of communication for religious people only. But further, adherents of certain religions are only able to communicate in their religious language with fellow adherents.

This understanding eradicates the suspicion of neo-positivism which denies the validity of religious language. Of course, religious language has different rules of play than the scientific language that is claimed to be the only valid language by neopositivists, but the symbols used in religious language are thus not without meaning and cannot be regarded as mere vibrations of feeling. With this, we can begin research on the language of religion.

But besides that, in linguistics it is also common to distinguish between "natural language" and "artificial language"; in this understanding "artificial language" (artificial language) is a language that is formalized so that it can be used accurately, as seen in the use of language in science and philosophy. Meanwhile, "natural language" (natural 
language) is the language used in everyday conversation. If the notion of language here is broadened as understood in the context of de Saussure's thought, then even religious language can be categorized as natural or natural language, as we shall explain below.

\section{Two Kinds of Language Usage}

In Language and Myth (1946) Ernst Cassirer also put forward a theory about two kinds of languages that differ in their use. The first language is representational, the second is discursive. In myths, for example, primitive people use representational language to describe natural events and life events. Their language expression is in the form of narration or narration of a story, to express the phenomenon that is still intact. Meanwhile, modern people use ratios to reason the same events and events, as shown in scientific exposures. In this distinction, representational languages are older because they precede discursive languages. According to Cassirer, discursive thinking is the result of further development of the human ratio.

These two kinds of language put forward by Cassirer seem to be in line with the separation between "natural language" and "artificial language" as understood by many linguists. Mythic language was born as "natural language", which tends to express the primordial feelings of humans spontaneously in admiration and fear in life. As also explained by Susanne K. Langer in Philosophy in a new Key (1942), this language originated from mere screams or muttering uncertainly. This language continues and crystallizes in the language of religion, in the event of ceremonies (rites) and narration of sacred stories (myths). While sophisticated "artificial languages" develop later, especially in their use in philosophical, scientific and technological thinking, when humans are able to distance themselves from life and reflect life objectively. It is for this purpose that "artificial language" was created in which technical terms were used that could better explain.

It is from this understanding of background that accusations may emerge, religious language as an expression of mere feelings. Such accusations may still apply to primitive religions that stop at the activities of mythical rites and narratives, with the aim of merely seeking security in life in this world, by adjusting to the desires of divine spirits. But seeing the development of modern religion whose activities cover a broader range of fields and with theological discourse that is no less sophisticated with philosophy, it seems naive to equate the language of modern religion with the expression of primordial feelings.

However, these two stages of language use still seem to leave their mark in the two kinds of roles of words in our daily language, namely the word for "refer" and the word for "review". For example, a child who is still in the learning phase recognizes the things around him, points to his doll while saying "tiger". Meanwhile, an adult who is learning a foreign language, English for example, says "tiger" to give the equivalent word tiger. In the first case, the child uses the word "tiger" to refer to an object that is 
intended. Of course, he will learn more about the real tiger, when his father takes him to the zoo. But in the second case, what matters is not the reference to the intended object or object, but the meaning of the word. Because the importance of the word in the second case is not to refer to, but to review the problem further, when he has to express it in the English language he studies. Furthermore, the word "tiger" is also understood in relation to other wild animals, or mammals. The importance of the word is to review a broader understanding.

In the first case, the word used to refer to reality supports the application of the language patterns of experience, while in the second case, the word used to review the problem supports the application of thought patterns. In the experience language pattern, the importance of the word as a "symbol" is its certainty, which is in accordance with the reality experienced, while in the language pattern of thought, the importance of the word as "concept" is the clarity of its "meaning", because this will determine the clarity of thought he said. So children begin to learn languages by using words that refer to various objects or items they encounter. It turns out that every object has a "name" as a reference word. In subsequent developments, the reference words may be replaced by other words, which are used to review or think about the problem more broadly and in detail, but initially, it must have a definite reference word that gives a picture that can be held firmly. After that they began to learn foreign languages and use foreign words, which are compatible with the reference words they learn. The word that originally functioned refers to the concept. The word "water" after its meaning is understood, can be replaced with aqua or water or $\mathrm{H} 2 \mathrm{O}$, the most important thing is that it has the same meaning, although each relates to different usage contexts. Aqua for example is a trademark, which is already used in everyday language when we need water in travel. $\mathrm{H} 2 \mathrm{O}$ is certainly not used at home, but rather at school, when we study chemistry and so on.

In "review" language, words act as technical terms, or instruments to further explain the experience. So the main interest here is not concrete things, objects, or experiences, "what" is from the speech, but rather the clarity of its meaning, in relation to other words in a speech area. The language of review is used inclusively, which summarizes the understanding of many people who have different experiences, but can compare their similarities. The more words or terms used are clarifying and universal, the broader the range of experience that can be reached, so that more people can talk. In other words, the language of review, supplemented by words as concepts, functions more for thinking and communicating.

In languages that "refer" instead, words take the place of the presence (representation) of things, things, or concrete experiences. Then the main interest is the integrity of words as a reference, to obtain certainty about the "what" from the experience. Referring language has a role to confirm belief in collective experience. The doubt that a member of the language user community refers to a certain word or 'symbol', can 
shake and cause other confusion. The solution is that the person must return to the agreed convention or terms of reference, or be expelled from the reference language community as an apostate, or a stranger who does not understand. Referring languages thus apply exclusively and function more as expressions or expressions that bind unity and deepen the intensity of their shared experiences rather than as a means of communication.

Just as representational languages in myths precede the emergence of discursive languages in science, words that refer to the language patterns of experience also precede words that review in language patterns of thought. In the process of mastering language, children first learn basic words that refer to concrete experiences, after enough vocabulary that refers to mastered, then he learns other words that are more abstract, which are loaded with expanded meanings to carry out thinking.

\section{Language that "refers" to religion}

In the context of religion, we use words that refer to describing religious experiences that directly point to the sacred things that are experienced. Difficult things are not uncommon here, because what is referred to by religion with these words is often not a sensory object that can be expressed, but rather an experience that Rudolf Otto called "tremendum et fascinosum" things that language analysts often suspect as feelings that are irrational. However, in the use of words that refer to religious language, it must be realized that human experience is very rich and is not limited to material things or related to sensory data. So as far as it is original experience, that too can be referred to in words. But language analysts apparently assume that what can be perceived with words is only sensory reality. This difference in opinion seems to be insurmountable. Furthermore, as JL Austin said, even in expressing sensory experience ordinary people are often uncritical because it equates sensory data with sense of reality. Modern philosophers, especially language analysts, seem to be very strict in establishing categories to determine what is meant by reality (reality), so that sensory data as a perception is still considered to be deceptive.

Words that refer to religious language are often used on various occasions, such as sacred ceremonies, sacrament reception, prayer elevation, chanting, credo, exorcism, teaching or catechesis, sermons in synagogues and so forth. In this practice the words spoken refer to the sacred situation, which is concerned with supernatural divine subjects such as God, angels, saints, spirits and so on. For people who are not interested or not followers of the religion, the words are foreign, not understood, and they easily put a priori wrong. This difficulty can be understood because the referring language mentioned above, is more expressive than communicative. That is why, the use of language referring to religion must be said, more internal and exclusive, meaning that it only applies to the interests of its adherents, because only they understand. This is in accordance with the principle of language games, where the rules of the game only apply or 
apply to the players only. The audience is not involved in the game and is not subject to sanctions.

In this referring language, words are definite symbols, which are natural or natural, about something divine, which are believed or believed to exist. In linguistics, people debate whether words emerge naturally or artificially, man-made. Apparently, this can be seen from two different angles. In mythic religious language, as Max Müller studied in ancient Hinduism, words are symbols that originate from natural events. The names of gods and divine events are representations of the names of nature, which are directly captured by humans and poured into mythic language. In Semitic religions, sacred names are given through revelation and are not created or made up by humans themselves. But getting closer to divine reality, these words not only describe or describe the attributes of divinity, but instead hide them as mysteries. That is the reality of the divine presence. The use of language that tries to expose or strip away the divine reality is considered frivolous and can bring danger. That is why religious language cannot fully explore reality as the language used in scientific books or for reviewing news in newspapers, for example. There is respect that must be maintained.

On the other hand, in a positive sense it can be said, that the use of words that refer to religious praxis can also bring benefits, meaning that there is a power that directly influences those words that carry out what is expected, because there humans enter the sacred territory or which divine power. According to van der Leeuw, words in the language of primitive religion are not concerned with the meaning, but rather the luck or power that arises from the use of these words. It is not uncommon for words to be considered taboo to pronounce, because they contain the danger of efficacy, for example in prayer, exorcism or mantras that are pronounced correctly and in accordance with very complex religious procedures.

In Genesis, the story of creation, God said "Be bright, so light will be" (Gen.1,34). The word of God makes (realizes) directly what it means (wants), without the need to explain it. That is efficacy in words referring to religion. This pattern applies also in the experience of religious people. When a religious person calls the word "Allah" with the whole experience of belief, then the intensity is different from a theologian or philosopher who says the same word in a lecture in class, because the word that refers to has a good orientation or blessing for the believer. The term becomes like a 'greeting' to something living, which is real. So the use of words that refer to prayer, ritual ceremonies, exorcisms, sermons at places of worship have different weights from the words that are reviewed in the presentation of science or politics outside the religious constellation. In the use of words that refer, what is important again is not the "meaning" to understand, but the intensity of the word, to get "blessing" and "good luck", which gives peace and safety. Real touches like this are experienced by religious groups such as charismatic prayer groups or mystical mystic groups.

There is indeed a strong emotive element when words are used to refer to them, 
because the user of that word has the disposition to be involved in the divine event it says. And to maintain this emotive atmosphere, words that refer are not only certain, but also call for change. Sacred words in religion, such as in mantras and prayers, are key words that remain irreplaceable, to unlock the primordial religious experience. Because they are fixed and unchanging, words can be recited and memorized. Significant main prayers have not changed from then until now. The more he refers to the sacred and divine reality, the more his words invoke change. And the words that are called, such as prayers, mantras, dogmas, credo, formulation in the rite, maintain the collective memory possessed by all people who embrace the religion, then the language of religion in this case also has a psychological bond.

But sometimes it happens, especially in primitive religion, this reference language is also used not to bring good luck to its adherents, but plagues to the enemies of religion. This applies in magic. The intensity of magic may have shifted into a phenomenon of terror and violence in the name of religion today, when magic is no longer believed to have the impact they want. However, in ancient religions, it was enough to mention the divine or supernatural name, they believed the plague would hit its enemies. However, modern critical religions seem to only direct religious ceremonies or rites to obtain prosperity, salvation, not only for their adherents, but also for the entire nation, the universe.

The referring language, of course, is not only used by individuals in that religion, but often together. This is possible, because adherents of the same religion have inner or spiritual experiences that are collective, so the use of the same words refers to the same memory as experiences of grace, acceptance of blessings, appearance of divine figures (hierophanias), illuminations (enlightenment), liberation and so on and evoke the same emotions. For those who are not followers of the religion in question, once again, those words will be considered superstitious, nonsense, hallucinations and so on. That is because they do not see, do not experience, and do not understand the phenomenon called these words. Thus it appears, how easily misunderstanded not only between the adherents of religion and scientists in the past, but also between adherents of different religions in the present, especially if among them already printed images of death from religious events past. Why?

Because sociologically religion developed in time, but the words that refer to primordial experience, as explained above turned out to be immutable and unchanging. So the picture of other religions often often settles in memory as part of an indelible old collective experience. As a result, injuries from religious conflicts in the past continue to be carried in the history of the development of religion and are very difficult to be eliminated, or even integrated in sacred myths. A clear example might be the "Crusades" or "Sabil Wars" between Christianity and Islam. Understanding a simple religion, not infrequently still brings this primordial experience, especially those who view other religions negatively. The collective memory, which denies other religions, often func- 
tions as a nutrient to strengthen the intensity of one's own religion. Because religion is the whole collective experience expressed in that language; then the language of religion in this case also has emotive power that binds strongly.

In this case religion needs to critically distinguish original experiences of the supernatural, as expressed in language that refers to distortive experiences or deceiving illusions. The role of modern science, such as the psychology of religion, the sociology of religion or the phenomenology of religion, with scientific language that reviews, helps critically provide clarification or evaluate these experiences. In general, dynamic religion will accept or at least learn non-religious information from these modern sciences to correct themselves.

Different from words that refer, or crystallize into representational symbols, words that review in religious language are not used in direct contact with supernatural experiences, but especially in horizontal communication with fellow believers and may extend beyond religious circles. that, as far as the words used have the possibility of developing in many other equivalents which have a general meaning. Different from words that refer directly to an entity or reality that is divine, the words in the language that are reviewing are concepts that contain meaning. People can understand it, though not completely, as long as they grasp that meaning, even though they don't experience it themselves. The meaning of the words in the review language can be understood, because it does not refer directly to the unique experience of religion, but rather to an understanding that can be applied in general experience, or which can be expressed in other words, which are compatible. Here applies an analogy. Thus, the word "saint" in Christianity, for example, is understood as a symbol or concept, the meaning of which relates to holiness, heroism in religious praxis, or with certain qualities that are prioritized by that religion. Such experiences also exist in other religions. Thus, the user of the language of review can compare analogically, for example with the hero in the praxis of statehood that has the virtues of patriotism, such as the defense of the motherland, the courage to die as a victim to defend the truth and so on.

The language of review, especially for users who are not followers of the religion, actually does not really care, whether the words they use refer to objective reality, because if things like this are disputed, controversy will arise as mentioned above, regarding the level of truth that must be verified with evidence. The review language used in theology presupposes its users still believe and accept certain words as references to true reality, because theology is still within the area of the religion in question. However, the language reviewed in the psychology or phenomenology of religion, does not presuppose these beliefs, but using the term phenomenology, these beliefs are enclosed in parentheses, postponed (epoche), because what matters is the meaning of the words, to be understood, not truth the reference. Or more accurately said, users of "language of review" who talk about religious phenomena are expected to have empathy, to at least respect the beliefs of those believers, even though he himself is not a follower 
and does not experience it. If this empathy does not exist, then the psychology of religion or the sociology of religion becomes useless science, because in that sense they will only talk about lies or empty words, imagination or superstitions that are denied by science itself.

Because it does not refer directly to religious experience, which involves divine or supernatural reality, the language of review can be used freely by people outside the religion. All that is needed is the clarity of the meaning of each word used, its relation to other words in various hermeneutic circles, such as words in a language dictionary, so that the reasoning can be explained by other words and understood. In this language, words are concepts that must and can be elaborated with other words consistently and coherently. In this sense the religious sciences do not judge the reality of religion, but merely describe it from various points of view.

In the context of Christian theology, for example, the word Trinity will relate to the words Father, Son and Holy Spirit, and not father, mother and child as in a family context. The words were revealed, not created. But in theology, new words or terms can be created for the sake of understanding, to explain the unspeakable phenomenon, as long as this new term can be grasped to explain, not to cloud. Thus the theology of religions developed. In this case the clarity of the concept has a practical importance in understanding. So it is different from the words in the language referring to certain and call, because given or revealed, words or terms, which are created and become concepts in the language of review are actually susceptible to changes. Because in this context there is no word that precisely defines meaning that is always changing, to pursue universal interests. Thus, theology as a language user who reviews in religion, is expected to always renew itself. Because the meaning of a word which was originally considered to be able to describe the typical experiences of local religious people, can shift when raised and understood by other people who do not experience the religion, or even because they are in another cultural area.

The context of this cultural experience has a strong influence on the understanding of words that are simply taken from other cultures. That is why theology has a very important role, to articulate every religious experience, so that it is not misunderstood and so that it remains current with the circumstances and conditions of local life. Contextual theology today increasingly develops the language of review, by allowing the emergence of new words, which are in accordance with and can be understood by local cultural interests, replacing classical theology that is still strongly bound by the referring language that is bound to the culture of origin of the religion. Classical theology often merely takes over religious terms from the original (foreign) language without giving sufficient discursive explanations. Thus, classical theology tends to maintain the originality of distinctive religious experience, but can be said to impose that experience on its adherents today, who have different cultural backgrounds and existential experiences, while modern theology or contextual theology, on the other hand, can be consid- 
ered to eliminate primordial experience religion, using new words, to pursue and emphasize religious understanding that is full of meaning.

\section{B. DISCUSSION}

The Scriptures are the most important texts in religion. As indicated in its "holy" nature or qualifications, this book refers to different divine or supernatural things or events, if not contrary to the "profane" and therefore declared sacred by religious adherents. In this capacity, it is very clear that the language of Scripture cannot be equated with ordinary, everyday or scientific language. The language of the Scriptures is the language of par excellence and therefore must be understood in the manner of the game. The Scriptures are not history, which tries to show facts in the past, in illo tempore. In the Ernst Cassirer category, the language of the Scriptures is included in the representational language, which presents an original religious event, while the language of history is discursive with definitive terms for reviewing facts. History tries to explain the meaning of past events to the general reader with detailed information and therefore must use language that is reviewing.

Different from the Scriptures, the history of the past must not be written in the language of the past where the meaning of the words is no longer understood by the present reader. History must be continually updated with language, and with that also its meaning, because the language of review is a dynamic language. While the language of the Scriptures emphasizes collective memory, to present the primordial event, so that the words that play a role in representing the divine presence are sacred and must not be changed. This is also closely related to the fact that the Scriptures originate from oral speech and are passed down by rote from generation to generation. Sacred words revealed must not be wrong in landing, because it will eliminate the sacred nature and power. Only later, orally revealed revelations began to be copied in writing, and became books. In such situations, memorizing, feeling and remembering texts is a more important ability than reading and understanding its contents.

Perhaps here it is necessary to explain a little difference between historical facts and religious phenomena, which concern divine events. First, historical facts are worldly and therefore can be measured hard or soft based on temporal evidence. The emergence of additional evidence will harden the position of the facts. Even so, historical facts are increasingly distant from the reader's situation due to time travel, and it is increasingly difficult to find additional evidence. That means, even historical facts can't reach a certain truth. The longer the event occurs, the greater the uncertainty. Meanwhile, divine events are believed to be supernatural events and are not subject to proof, because what is being pursued is not facts but messages. As something sacred, divine or supernatural events have a high persuasive power to carry out and not just know about. Then the proof of the divine event actually degrades the phenomenon into mere profane facts that lose their persuasive power. Religious belief is sufficient as justi- 
fication for oneself, as a sign of willingness and humility to receive revelation.

Second, historical events have a relative significance compared to the divine phenomenon, which determines the safety of religious people. This distinction further complicates the issue of language referring to in the Scriptures, because for the sake of its sacred nature regarding the divine phenomenon, the language of reference does not require renewal like the language reviewed in historical analysis. The divine phenomenon contained in the Scriptures is not exposed to a touch of temporality which demands a change of language. That is why, the Scriptures are eternal, do not undergo language renewal.

Because it refers directly to supra temporal things or divine events, the language used is standard, or even frozen, but firm and certain. The more things or events that are divine, the more necessary the words or language they use are maintained, so that the substance of the original experience does not shift. This arrogance and certainty need to be maintained by tradition in the original language. That is why the language used by the Scriptures has a high position, because it is the main language, with which the divine manifests itself. In the phenomenology of religion, the holy language is called the Holy Writ. All major religions have their own sacred language, that is, the native language that is recognized as sacred because it refers to the divine event as contained in the Holy Book. Generally this sacred language is the language of the region from which the religion originated.

But in Christianity, the use of Latin as a holy language began to be sued by Luther (1483-1546), because it was felt to hamper the experience of living faith. After all, Latin is not the original language of the Christian Scriptures. The Latin language was only officially used by the Church in the fourth century, after all translations of the Scriptures into Latin were completed by St. Jerome (347-420) and later colored the development of Church theology in the Middle Ages. This difference in claims over sacred languages had a profound effect on the controversy between the Catholic and Protestant Churches regarding the canonization of Scripture. Originally the Scriptures were written by various people in Aramaic, Hebrew and later also Greek, especially those written outside of Palestine. Therefore, the translation of the Scriptures pioneered by Luther into German in the sixteenth century, did not base itself on vulgata, the official canon in Latin, but rather the manuscript in its original language. This initiative was then followed by other Christian denominations. Officially Catholicism retained Latin as a sacred language until the Second Vatican Council.

Because of the importance of referring to the language of Scripture, many religions were initially very strict in regulating translations. In the Catholic Church, even after the Second Vatican Council the Scriptures began to be translated and used in various regional languages, for the sake of developing understanding of their meaning, the Church still strictly distinguished words quoted directly from Jesus' own words, called ipsissima verbs from words other words that come from the gospel writers them- 
selves. Thus even though theological interpretation uses the language of review, theological thought must still go back to the basis of Jesus' original words in the referring language. The proclamation of faith must start from and return to this ipsissima verb.

This change in Christian attitudes toward the position of the holy language was motivated by the development of understanding, that the Scriptures are not divine words in their literal sense, but their spiritual inspiration. Meanwhile it was agreed that his expressions in written form needed human hands and thoughts too. This idea was supported by Pope Pius XII who in the encyclical Divino Afflante Spiritu (1943) advocated literary and cultural studies, which opened up the possibility and insight into scientific interpretation of Scripture. This change in teaching has further implications, that the understanding of the language of the Christian Scriptures has shifted from the language which purely refers to the language that is reviewing as well. Language that refers, for example, applies to the words of Jesus which are highly respected, while the narrative has an element of review as well, which pursues the meaning of understanding. So for Christians, the qua liber Scriptures are not sacred items. The sacred is the message contained in these writings. Therefore in the Scripture lecture, Christians can give notes, scribbles or anything in their Scriptures, to be able to understand their meaning further. Then the interpretation of the Scriptures which were originally spiritual and textualistic shifted to a scientific interpretation to find original meanings so that they could be utilized in relation to the actuality of life.

However, when compared to theology, the language of the Scriptures still shows more reference characteristics. That means, although it may be translated into other languages, the translation must be standardized, official and as far as possible literally, not to shift the original meaning. Of course this business is something that is not easy. The shift in meaning will always be looming in translation efforts, because the change in language implies a change in the context of understanding. Of course, to preserve the authenticity of its meaning, which brings blessings, is most perfect if the Scriptures are not translated at all. People read it or more accurately recite it in the original language, but with the consequences he did not understand its meaning. Only experts have the ability to know the language of the Scriptures. In this sense, the understanding of the church only follows what is taught by the interpreters. Right and wrong understanding depends on it.

In Christianity today, ordinary people also have the right to interpret and understand for themselves what God has said. In this sense the Scriptures need to be translated. But in order to be the basis for a healthy interpretation, the translation needs to be standardized and formalized. The people can indeed read and understand the Scriptures themselves in the translated text, with the risk of course, there is wide open interpretation. But even this openness does not destroy unity, because besides that, Scripture experts still have high authority in terms of interpretation. Because in addition to textual knowledge, they have knowledge of all contexts, narratives and cultural backgrounds 
of the Scriptures.

Different from the language of theology which is really reviewing, the language of the Scriptures is still considered more standard, because it is officially established. In the case of translations, for example, Church authorities will determine which translations are standard and recognized. This means that the reference nature of the language in the Scriptures is not completely eliminated. The Scriptures can be said is an expression of faith of the first people, which is still close to the original experience, in illo tempore, togetherness with the living Jesus, which gives rise to a feeling of "tremendum et fascinosum", which touches on the Jesus event as it is, raw and has not been reflected in the mind and the whole nuance of empathy. Then the Scriptures are considered to contain original experiential truths. Theological language is instead an interpretive language, which tries to explain its meaning, which is blurred by the gap of time and place, between the text and the reader, or is hindered by the accessories, the complement of knowledge, a methodological a priori, which accumulate in the minds of today's readers. Theology with logical, systematic and comprehensive language, trying to build bridges, or trying to create telescopes (or microscopes, aiming for their interests), or just rubbing their eyes so they can see the original experience of the text of the Bible more clearly.

Compared to the writing about history, the object of theological interpretation is the meaning contained in the Scriptures, while the object of historical interpretation is the event itself. In the Gospels Jesus' events are not analyzed as facts, but as meaning. So the historical event is not compared with the divine phenomenon in the Scriptures, but with the text. Therefore, in Christianity it is also possible for people to study the history of texts as facts, because the writing of the Christian Scriptures is a human activity like other historical events. Further study of the text of the Scriptures as far as they are concerned is expected to clarify the meaning contained therein. With this approach the interpretation of the meaning of the Christian Scriptures avoids the danger of mythology, which deifies the text but obscures the meaning. Of course in this case there is a hermeneutic issue which opens up many problems in the interpretation of the meaning of the Scriptures.

Lately we often talk about religious pluralism with presuppositions as if the problem is simple. Not infrequently, people enter this problem with a moralistic perspective, with optimistic presuppositions about shared life between various religions, calling for tolerance and sincere dialogue between religions for the achievement of peace. But moralists and initiators of religious dialogue, driven by passionate goodwill (benevolentia) and the desire to dispel mutual suspicion, are often less critical to understanding the profound differences between religions. The reality of religious pluralism also raises a difficult question to answer, namely, can religious differences be bridged? Can different religions dialogue with one another? 


\section{CONCLUSION}

An analysis of the language of religion in this essay can more or less help to understand the extent to which religious dialogue and communication can be carried out. As can be seen from the above description, religions can dialogue their teachings and beliefs as long as the material is expressed in "reviewing" language. In this case the theology of religions can develop properly. However, because the language of review does not refer to concrete religious experiences, but rather to abstract concepts and meanings, this dialogue can only end in a very limited mutual understanding of practices and teachings, and has less impact on the formation of common sense or empathy.

Meanwhile, the language "referring" is only possible to mutually reinforce beliefs exclusively and internally, meaning that it is limited to fellow believers of the same religion. This understanding is only understood in the sense of expressing the same religious experiences and feelings and not dialoguing or discussing the revealed divine reality. In other words, it is impossible to do religious dialogue internally. But this is indeed not felt as a need, because they are of the same understanding (brethren).

However, it cannot be concluded just like that, because it is not possible to hold a religious dialogue then there will automatically be violence between religions. The gap between religions that is not bridged by dialogue through religious language is one thing, religious violence is another thing. Each must be examined according to the nature of the problem itself, because it has nothing to do with each other. Religious violence socially must be overcome through approved legal channels and not through religious dialogue, as with other acts of violence. Meanwhile, there is still a complicated problem, how can the differences between religions be overcome, if the language of religion is unable to overcome this problem. But the problem is, religious dialogue is not to seek equality and agreement, but rather, it is sufficient if it shows effort, to understand each other. To achieve results that are further from this, other deep thoughts might be needed.

\section{REFERENCES}

1. Austin, J. L., \& Warnock, G. J. (1962). Sense and Sensibilia (Vol. 83). Oxford: Clarendon Press.

2. Bellah, R. N. (2011). Religion in human evolution. Harvard University Press.

3. Brass, P. R. (2005). Language, religion and politics in North India. iUniverse.

4. Brenner, L., \& Last, M. (1985). The role of language in West African Islam. Africa, 55(4), 432-446.

5. Brubaker, R. (2013). Language, religion and the politics of difference. Nations and nationalism, 19(1), 1-20.

6. Burke, K. (1970). The rhetoric of religion: Studies in logology (Vol. 188). University of California Press. 
7. Cassirer, E. (1946). Language and Myth. New York: Dover Publications Inc.

8. Derrida, J. (2002). Acts of religion. Psychology Press.

9. De Saussure, F. (2011). Course in general linguistics. Columbia University Press.

10. Edwards, J. (2009). Language and identity: An introduction. Cambridge University Press.

11. Edwards, P. (1967). The encyclopedia of philosophy. New York, 2, 176.

12. Habermas, J. (2006). Religion in the public sphere. European journal of philosophy, 14(1), 1-25.

13. Irvine, J. T., Gal, S., \& Kroskrity, P. V. (2009). Language ideology and linguistic differentiation. Linguistic anthropology: A reader, 1, 402-434.

14. Joseph, J. (2004). Language and identity: National, ethnic, religious. Springer.

15. Kouega, J. P., \& Baimada, F. G. (2012). Language use in the Islamic faith in Cameroon: The case of a Mosque in the city of Maroua. Journal of Language and Culture, 3(1), 10-19.

16. Lawson, E. T., \& McCauley, R. N. (1993). Rethinking religion: Connecting cognition and culture. Cambridge University Press.

17. Masuzawa, T. (2005). The invention of world religions: Or, how European universalism was preserved in the language of pluralism. University of Chicago Press.

18. McFague, S. (1982). Metaphorical theology: Models of God in religious language. Fortress Press.

19. Omoniyi, T., \& Fishman, J. A. (Eds.). (2006). Explorations in the Sociology of Language and Religion (Vol. 20). John Benjamins Publishing.

20. Proudfoot, W. (1985). Religious experience. Univ of California Press.

21. Schiffman, H. F. (1998). Linguistic culture and language policy. Psychology Press.

22. Spolsky, B. (2009). Language management. Cambridge University Press. 